\title{
Thermal Efficiency Comparison of Different Injector Constellations in a CI Engine
}

\author{
Author, co-author (Do NOT enter this information. It will be pulled from participant tab in \\ MyTechZone) \\ Affiliation (Do NOT enter this information. It will be pulled from participant tab in MyTechZone)
}

\begin{abstract}
More stringent emission regulations call for high-efficiency engines in the heavy-duty vehicle sector. Towards this goal, reduced heat losses, as well as increased work output, are needed. In this study, a multiple injector concept to control the combustion as well as reduce the hot boundary zones is proposed. Earlier studies have proven that multiple injectors experience lower heat losses and higher efficiency. However, a comprehensive investigation of the causes for experimental heat loss was not performed in depth. Experiments in a heavy-duty CI engine equipped with three injectors were thus performed. Engine configurations of single, dual and triple injectors were compared for a single-injection case as well as a multi-injection (Sabathe-cycle) case. Heat losses, efficiency and the emission levels were quantified and investigated. Optical experiments were performed to investigate the temperature field as well as flame behavior. This led to further understanding of the heat loss drivers. Experimental data was coupled with the double compression expansion engine concept for waste heat recovery, utilizing the energy from reduced heat losses. Notable findings included an efficiency increase of $1.9 \%$-points when using all three injectors for a single injection. Three injectors improved the efficiency an additional $1.2 \%$-points in a Sabathe-cycle case as compared to a single injector case. These gains mainly followed by reduced heat losses caused by hot zones being kept away from the boundaries. Thus, the benefits of multiple injectors were proven.
\end{abstract}

\section{Introduction}

With a growing strive for reduced greenhouse gas emissions, a lower fuel consumption of heavy-duty vehicle engines is desired [1,2]. Possible strategies include engine efficiency improvement. Gains in efficiency can be achieved by simultaneous reduction of different engine losses such as heat and exhaust losses.

Towards this goal, several advanced engine concepts have been proposed. One such concept is the homogenous charge compression ignition (HCCI) engine [3]. This concept aims to combine the benefits of CI and SI engines by having a homogenous charge, to minimize emissions, as well as low-temperature combustion, to reduce heat transfer to the walls. In a previous study, low NOx emissions, as well as low heat losses, were claimed [4]. However, difficulties such as controlling the heat release and low load ignition were highlighted.

Another concept, namely partially premixed combustion (PPC) [5] aims to solve the flaws of the HCCI concept. The PPC utilizes an

Page 1 of 11 earlier injection than typical CI combustion for an increased premixed burn. Experiments have previously been performed with different fuels to investigate the PPC in an HD engine [6]. Lower heat losses, as well as high efficiency, were claimed. High-octane fuels, with longer ignition delay, were found beneficial to enhance the performance for PPC efficiency due to enhanced mixing. However, the combustion control, at early injection, diminishes at high loads.

Another advantage of heat loss reduction is increased potential of enhanced engine work output [7]. A previously proposed solution, to utilize reduced heat losses, is the double compression expansion engine (DCEE) [8]. This concept uses a split-cycle with two cylinders leading to a high combined compression ratio. A larger cylinder compresses the intake air before transferring it to a smaller cylinder where combustion takes place. At first, the smaller cylinder performs an expansion. Secondly, the residual gases are transferred back to the larger cylinder for a second expansion. Efficiencies of up to $56 \%$ have been reported for the DCEE [9]. However, high heat losses are reported due to the high compression ratio (above 60:1), thus motivating a heat loss reduction.

Reduction of local emissions, such as NOx and CO, in heavy-duty vehicles, experience progressively stringent regulations [10]. Thus, a solution for reducing local emissions is needed. A trade-off between fuel economy and NOx exists due to the increased in-cylinder temperature experienced at high-efficiency combustion [11]. Thus, a solution for simultaneous reduction of NOx and increased efficiency is needed. CI engine soot emissions origin from fuel-rich zones [12] meaning a decrease of local rich zones is also desired.

In order to solve the problems highlighted above, a CI engine utilizing multiple injectors has been proposed [13]. Two injectors placed at the rim of the bowl, along with the standard central injector, were used. A higher efficiency, along with reasonably low local emissions levels, were claimed in this study from experimental results. It was suggested that reduced heat losses followed by the reduced flame/wall interaction. However, this lower flame/wall interaction was not confirmed and needs to be studied further. Other computational studies have confirmed the heat loss reduction using multiple injectors $[14,15]$. In these studies, CFD simulations were performed to investigate how two injectors can reduce heat losses and increase the efficiency of an HD CI engine. Reduced heat losses of $4.2 \%$-points as well as increased efficiency of $1.9 \%$-points were achieved. Furthermore, it was stated that a lower amount of flame/wall interaction occurs when utilizing multiple injectors. However, further experimental investigation to highlight the cause of reduced heat losses was emphasized an area of interest. 
In this study, experiments to investigate the reason for reduced heat losses, due to the utilization of three injectors, were conducted in a heavy-duty single-cylinder engine. Different injector constellations were utilized and compared for further understanding of multiple injector combustion. Heat losses, efficiency as well as emission levels were quantified and evaluated. Expected results include lower amounts of flame/wall interaction when utilizing multiple injectors and thus lower heat losses followed by increased efficiency. The scope of this work also consists of an investigation of total efficiency gain, from reduced heat losses, when the Double Compression Expansion Engine is utilized.

\section{Methodology}

Experiments on a two-liter single-cylinder direct-injection CI engine were conducted to investigate how multiple injectors reduce heat losses. Table 1 summarizes the properties and specifications of the engine used herein. The injector setup, as shown in Figure 1 contains the standard, centrally mounted, injector alongside two injectors placed at the rim of the piston bowl. The outer injectors spray in a swirling motion to avoid spray/wall interference. A high-pressure common rail (3000 bar maximum pressure) was utilized for the diesel injection. The injector's electronic control system allows simultaneous injection from all three injectors.

A hydraulic variable valve actuation (VVA) system was utilized for intake and exhaust valve control. An external supercharger controls the intake pressure coupled with an air heater controlling the intake temperature (see Figure 2 for full engine layout). This engine setup follows a previous experimental study [16]. The drive current of the injector was measured using a Hioki CT7631 current probe. From this measurement, the injector signal was taken. The in-cylinder pressure was measured using a Kistler Model 6043AU20SP piezoelectric sensor. The pressure sensor is mounted from the cylinder head and located at the outer edge (squish area) of the combustion chamber. For pressure data, digital filtering and ensemble averaging are used on the sampled data. Digital filters are processed at $3 \mathrm{kH}$. Ensemble averaging is performed on 50 data points for the filtered signal.

From the measured pressure, the rate of heat release was calculated from the definition as follows

$\frac{d Q}{d \theta}=\frac{1}{\kappa-1}\left[V \cdot \frac{d P}{d \theta}+\kappa \cdot P \cdot \frac{d V}{d \theta}\right]$

Where $\mathrm{P}$ is the pressure $[\mathrm{Pa}], \mathrm{V}$ the chamber volume $\left[\mathrm{m}^{3}\right], \kappa$ specific heat ratio, $\theta$ crank angle degrees, and $\mathrm{Q}$ the heat released $[\mathrm{J}]$.

To omit pumping work, the heat balance estimation assumes a closed cycle without gas exchange [17]. Consequently, from the start of compression to the end of expansion, the law of energy conservation was used as follows

$$
\begin{gathered}
Q_{f}=W_{i}+Q_{\text {loss_ex }}+Q_{\text {loss_wall }}+Q_{\text {other }}= \\
=\left(W_{b}+W_{\text {loss_mech }}\right)+Q_{\text {loss_ex }}+Q_{\text {loss_wall }}+Q_{\text {other }}
\end{gathered}
$$

Where $Q_{\mathrm{f}}[\mathrm{J}]$ is the input energy by fuel. $W_{\mathrm{i}}[\mathrm{J}]$ is the gross indicated work during compression and expansion stroke. $Q_{\text {loss_ex }}[\mathrm{J}]$ is the

Page 2 of 11 difference between the internal energy of the intake gas and exhaust gas. $Q_{\text {others }}[\mathrm{J}]$ includes the unreleased energy by $\mathrm{HC}$ and $\mathrm{CO}$ emissions, the latent heat of the fuel and endothermic energy to form NOx. $W_{\mathrm{b}}[\mathrm{J}]$ is the brake work obtained from the engine dynamometer torque measurement. $W_{\text {loss_mech }}[\mathrm{J}]$ is the mechanical loss calculated by subtracting $W_{\mathrm{b}}$ from $W_{\mathrm{i}}$. Finally, the heat losses to the cylinder walls, $Q_{\text {loss_wall }}$ of unknown quantity is given by

$$
Q_{\text {loss_wall }}=Q_{f}-\left(W_{i}+Q_{\text {loss_ex }}+Q_{\text {other }}\right)
$$

Table 1, Engine properties and specifications

\begin{tabular}{|l|l|}
\hline Engine Type & DI Single Cylinder VVA 4 Valve \\
\hline Displacement & $2.004 \mathrm{~L}$ \\
\hline Bore x Stroke & $\varnothing 135 \mathrm{~mm} \times 140 \mathrm{~mm}$ \\
\hline Engine Speed & $1000 \mathrm{rpm}$ \\
\hline Swirl Ratio & 0.9 \\
\hline Injector & High-Pressure Common Rail \\
\hline Nozzle, Central Injector & $\begin{array}{l}\emptyset 0.179 \times 9-150^{\circ} \text { (Flow Rate: } 1750 \\
\left.\mathrm{~cm}^{3} / \mathrm{min}\right)\end{array}$ \\
\hline Nozzle, Outer Injectors & $\emptyset 0.265 \times 2$ (Flow Rate: $\left.870 \mathrm{~cm}^{3} / \mathrm{min}\right)$ \\
\hline Piston Type, Metal & Forged Piston (Monotherm) \\
\hline Piston Type, Optical & Sapphire Glass Piston \\
\hline Combustion Chamber & Soup Plate \\
\hline Compression Ratio & $18.0: 1$ (Steel, Base) \\
\hline Valve Actuation & Camless Hydraulic VVA \\
\hline Air Charging System & External Supercharger \\
\hline Test Fuel & $\begin{array}{l}\text { Diesel Fuel JIS \#2 (Cetane Number: } \\
58.3, \text { Sulfur content: } 8 \text { mass ppm) }\end{array}$ \\
\hline
\end{tabular}

A steel, as well as an optical piston, were used in this study. The optical piston allowed high-speed imaging visualization of the combustion chamber through the piston bowl. Resulting pictures were analyzed using the two-color method as described in previous studies [18]. This allowed the visualization of a temperature field inside the cylinder to identify the hot zones. The two-color method is based on the temperature measurement theory by Hottel \& Broughton and measures the temperature of in-cylinder gases by calculating the temperature of luminance brightness of two wavelengths such as red and green [19]. Here, the wavelength dependence coefficient used is 1.38 , following a previous study [20].

The average in-cylinder temperature estimated according to the following equation

$T_{(\theta)}=\frac{P_{c y l(\theta)} \cdot V_{c y l(\theta)}}{W_{g(\theta)} \cdot R_{g(\theta)}}$

Where $P_{\operatorname{cyl}(\theta)}$ is in-cylinder pressure, $V_{c y l(\theta)}$ is the cylinder volume, $W_{g(\theta)}$ is the gas weight, $R_{g(\theta)}$ is the gas constant which is calculated considering gas composition.

The gas weight is calculated via

$$
W_{g(\theta)}=W_{i a}+W_{e g r}+W_{r g}+W_{h b(\theta)}
$$


Where $W_{i a}$ is the intake air weight, $W_{e g r}$ is the EGR gas weight, $W_{r g}$ is the residual gas weight and $W_{h b(\theta)}$ is the weight of burned fuel given by

$W_{h b(\theta)}=\frac{Q_{\theta}}{1000 \cdot H_{u}}$

Where $Q_{\theta}$ is the total heat released and $H_{u}$ the lower heating value set equal to $43 \mathrm{MJ} / \mathrm{kg}$.

Heat losses and effective compression ratio change for an optical piston as compared to the metal setup. This follows from the altered wall heat transfer coefficient and increased blow-by. Thus, the intake pressure and temperature was altered to match the metal setup rate of heat release (RoHR). This strategy meant the optical cases matched the metal cases to a larger extent. Consequently, the optical experiments were used to visualize the in-cylinder behavior of metal experiments.

Engine-out emissions were measured in this study. A HORIBA Model MEXA9100 was used for engine-out NOx, CO, and HC measurements while an AVL Model 415S smoke meter was used for soot measurements.

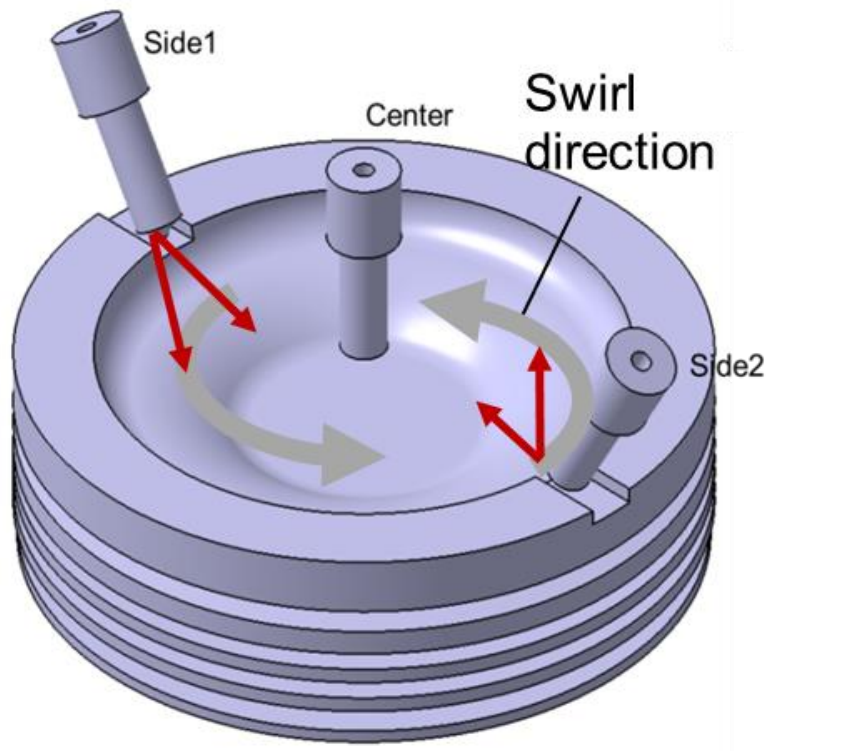

Figure 1, Injector configuration where 1, 2 and 3 injectors can be utilized simultaneously

A full view of the optical visualization system can be seen in Figure 3. The piston extension made bottom-view of the combustion chamber possible. A mirror was mounted below the optical piston to allow camera visualization. The observation field is limited to the piston bowl with a diameter of $85 \mathrm{~mm}$ as opposed to the bore of 135 $\mathrm{mm}$. A correction of the images was performed due to the piston hump refracting the seen light. Thus, the squish volume is not visualized with this setup. There is also no possibility of a threedimensional vision field. Consequently, in later analysis, conclusions of flame/wall interaction are drawn based on the end of the vision field where possible hot zones are assumed in contact with the piston.

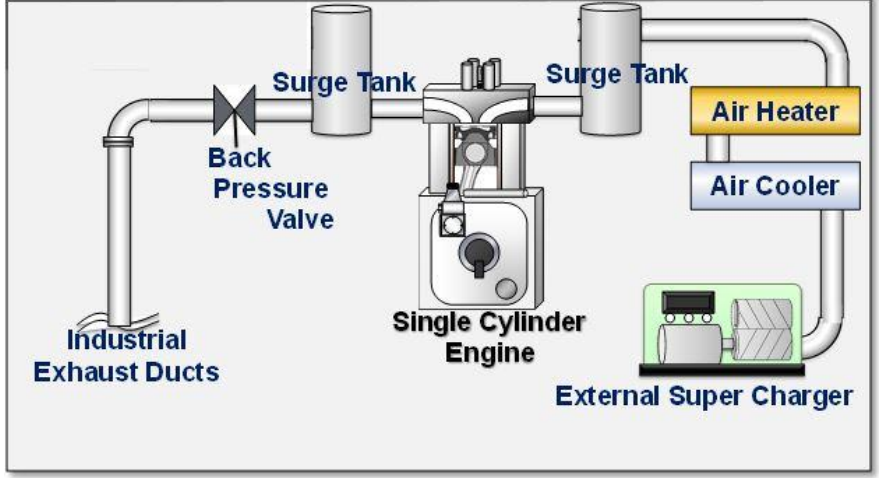

Figure 2, Single Cylinder Engine layout

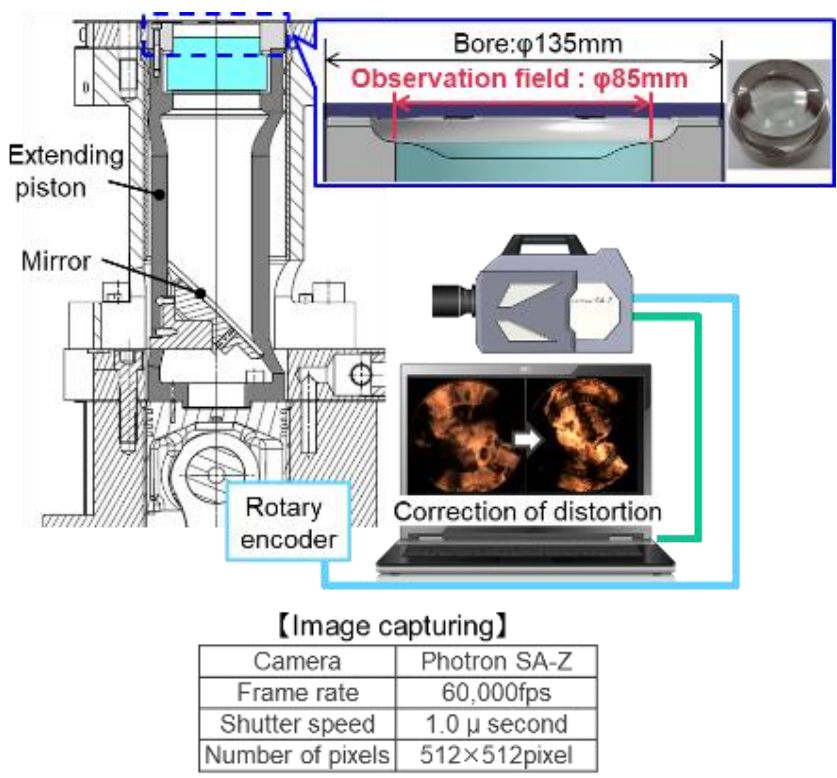

Figure 3, Bottom-view optical system

\section{Experimental Approach}

In order to compare the heat losses as well as combustion characteristics of altered injector constellations, a number of experiments were performed (see Table 2). One, two, and three injectors were utilized for both the optical and metal setups. A typical $\mathrm{CI}$ engine heat release profile was compared to a Sabathe cycle case, earlier showing high-efficiency potential [11]. These two rate shapes were used with one, two, and three injectors. Consequently, an altered injection duration due to the changed flow rate was used.

All investigated cases are listed in Table 2 with detailed information on injection timing. Abbreviations used include $\mathrm{C}$ for central injection, $\mathrm{S}$ for side injection from both side injectors and Three when all three injectors are used at the same time. As an example, the side-side (SS) case translates to an injection from the outer two injectors at two different times. The fuel amount was divided equally between the first and second injection. Notably, the injection timings were slightly altered for different cases. 
Table 2, Experimental cases matrix

\begin{tabular}{|l|c|c|c|c|}
\hline \multirow{2}{*}{ Case } & \multicolumn{2}{|l|}{$\begin{array}{l}\text { SOI [CAD ATDC], } \\
\text { Central Injector }\end{array}$} & \multicolumn{2}{l|}{$\begin{array}{l}\text { SOI [CAD ATDC], } \\
\text { Side Injectors }\end{array}$} \\
\cline { 2 - 5 } & $1^{\text {st }}$ inj. & $2^{\text {nd }}$ inj. & $1^{\text {st }}$ inj. & $2^{\text {nd }}$ inj. \\
\hline Central (C) & -8.5 & - & - & - \\
\hline Sides (S) & - & - & -8.25 & - \\
\hline All Three (Three) & -6.5 & - & -6.5 & - \\
\hline $\begin{array}{l}\text { Central-Central } \\
\text { (CC) }\end{array}$ & -8.25 & 3.75 & - & - \\
\hline Central-Sides (CS) & -8.25 & - & 1.75 & - \\
\hline Sides-Central (SC) & 1.5 & - & -8.75 & - \\
\hline Sides-Sides (SS) & - & - & -8.75 & 1.5 \\
\hline
\end{tabular}

The target for the Sabathe-cycle cases was to achieve a permanent part of isochoric as well as isobaric combustion to match the highefficiency case discussed before. This was performed by altering the injection timings slightly. For the single-injection cases, the injection timings were adjusted to match the peak of heat release, meaning that CA50 was kept reasonably constant for the single-injection cases as well as the Sabathe cases. For detailed experimental conditions, see Table 3.

Table 3, Experimental conditions used in all cases

\begin{tabular}{|l|l|}
\hline Parameter & \\
\hline Lambda & 2.5 \\
\hline Inj. Pressure & $2000 \mathrm{bar}$ \\
\hline Fuel Amount & $\begin{array}{l}102 \mathrm{mg} / \mathrm{cycle}(22 \mathrm{bar} \\
\text { FuelMEP })\end{array}$ \\
\hline Inlet Temp. & $323 \mathrm{~K}$ \\
\hline Intake Pressure & $1.7 \mathrm{bar}$ \\
\hline EGR & $0 \%$ \\
\hline IVC/IVO & $550 / 368$ CAD ATDC \\
\hline EVC/EVO & $355 / 170$ CAD ATDC \\
\hline
\end{tabular}

\section{Results}

This section presents the heat loss reduction and efficiency increase experienced with multiple injectors. Injector constellations are compared and discussed in terms of above-mentioned parameters. Emission levels are also presented and compared with a focus on local emissions. Finally, a double compression expansion engine is used for waste heat recovery to investigate the potential for total efficiency gains.

Page 4 of 11

\section{Injector Constellation Comparison}

As discussed earlier, three different injector constellations were compared. Namely one, two, and three injector cases. Here, performance measurements will be analyzed from the metal engine results. The optical cases will be used to visualize temperature fields from combustion and explain physical phenomena.

Figure 4 shows the heat balance for all metal experiments. Comparing the single-injection cases, it is seen that the $\mathrm{S}$ and Three cases have lower heat losses compared to the $\mathrm{C}$ case. Notably, this more moderate heat loss comes with a higher brake work in the Three case. This fact needs to be investigated further since higher work output, through faster combustion, is associated with higher heat losses in the typical CI case [21]. Here, the opposite trend is observed. For the S case, however, the brake work is reduced compared to the $\mathrm{C}$ case and thus following the trend from previous studies. Exhaust losses follow the analogy of heat losses with higher exhaust losses for reduced heat losses. As expected, the mechanical losses are comparable for all single-injection cases since combustion timing is similar. It is here concluded that using only side injectors is not beneficial for direct work output. However, using all three injectors give higher work output and efficiency.

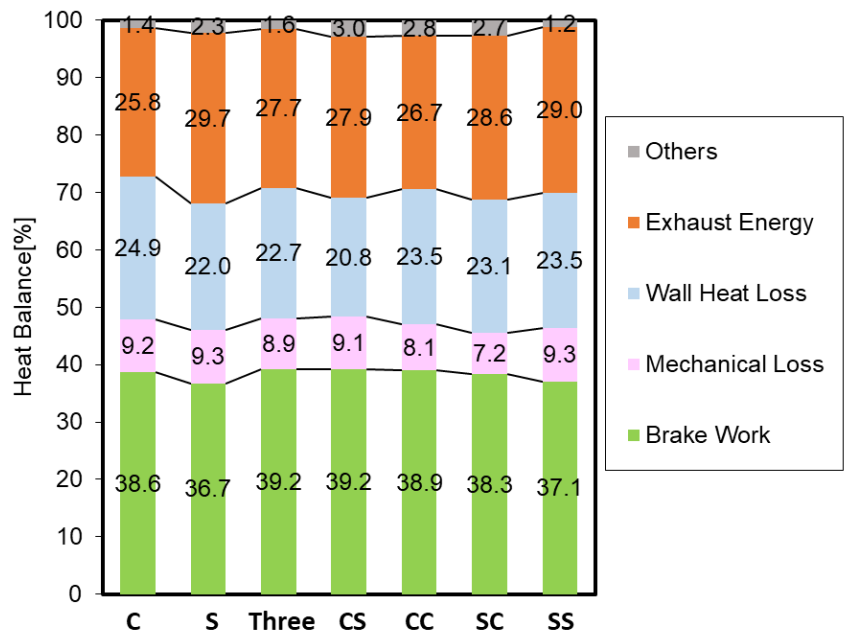

Figure 4, Heat balance highlighting the different areas of energy loss

For the Sabathe-cycle cases, the CS case shows the most significant heat loss reduction as well as the highest brake work (see Figure 4). A heat loss reduction of $4.1 \%$-points and a brake work increase of $0.6 \%$-points was achieved. Thus, it is considered the most optimal case of the Sabathe cases investigated here. The case utilizing only the central injector (CC-case) shows relatively high brake work while the heat losses are high. Another case showing both high heat losses and low brake work is the SS case. Mechanical losses changed with altered injector constellation. The SC case experiences the lowest mechanical losses. An explanation for this is the somewhat earlier combustion meaning reduced side forces. With these cases, it is concluded that utilizing three injectors is beneficial for keeping heat losses low and brake work high simultaneously.

From the optical images (see Figure 5), some important conclusions of the performance discussed above can be drawn. The high heat losses for the $\mathrm{C}$ case is related to the hot temperature zones close to the piston wall. These zones are seen close to the edge of the optical vision field. Here, the volume is narrow and hot gases assumed in 
contact with the piston. These locally hot temperature zones are not seen for the $\mathrm{S}$ case and Three case. Thus, convective heat transfer is higher for the $\mathrm{C}$ case. With the high flow rate of all three injectors, the Three case has a more uniform temperature distribution. Thus, it is concluded that this case utilizes the combustion chamber volume to a larger extent while keeping hot zones away from the piston walls. This explains how the Three case can have simultaneously reduced heat losses and increased work output. The $\mathrm{C}$ case's local hot zones are, in this bowl geometry, pushed towards the hump (dashed lines in Figure 5). This part of the surface is a large area zone, increasing heat transfer. It follows that three injectors solve the typical trade-off between heat losses and work output.

From Figure 5, it is also seen that the side injections change the flow pattern. The central sprays are forced in a swirling motion, effectively moving the hot zones away from the piston walls. For the $\mathrm{S}$ case, when all fuel is injected from the side injectors, the spray penetration is longer due to the smaller area for mixing. This means that some of the hotter gases reach the piston walls. However, these zones are smaller compared to the $\mathrm{C}$ case at $10 \mathrm{CAD}$ ATDC. This smaller mixing area also explains the lower work output through slower combustion for the $\mathrm{S}$ case.

It is again concluded, from the pressure and RoHR traces (see Figure 6), that the increased flow rate from the Three case results in a fast heat release. However, the lower pressure around TDC, compared to the $\mathrm{C}$ case, results in lower initial work output. This is compensated by a higher pressure late in the cycle due to the reduced heat losses. Thus, the total indicated work is higher for the Three case compared to the $\mathrm{C}$ case. The $\mathrm{S}$ case shows slower and more unstable combustion resulting in lower work output but simultaneously lower heat losses.

As discussed, from the optical analysis, this is partly due to the smaller surface area of the sprays leading to less mixing. Another explanation is the flame/piston interaction caused by the injector umbrella angle. Thus, the pressure rise is not as fast as for the other cases around TDC. In turn, the heat losses are lower later in the cycle. However, this is not enough to recover the lost work in comparison to the $\mathrm{C}$ case.
C-case: OCAD
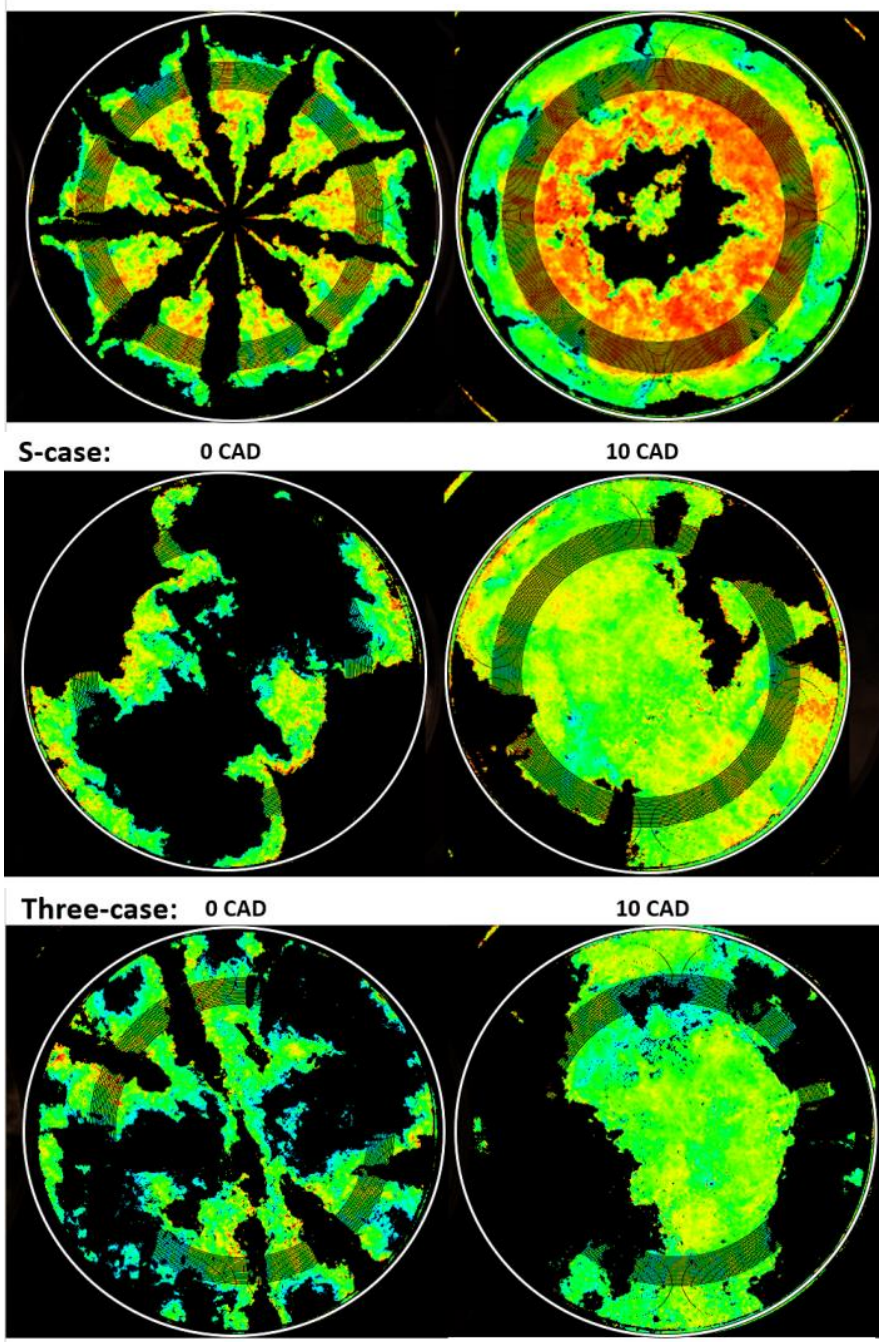

Figure 5, Optical temperature contours for the single-injection cases at 0 and 10 CAD ATDC

The average in-cylinder temperature (see Figure 7) follows the same pattern as the pressure discussed above. Due to the low early RoHR, the $\mathrm{S}$ case experiences lower in-cylinder temperature compared to the other cases. It is also seen again that, although the heat loss is lower for the Three case, the in-cylinder temperature is equivalent for the $\mathrm{C}$ and Three cases. Later in the cycle, the temperature is higher for the Three case due to the lower heat losses sustained. Again it is concluded that even with a higher in-cylinder temperature, the heat losses can be reduced when utilizing multiple injectors. This is achieved by keeping hot zones far from the boundaries as discussed before. 


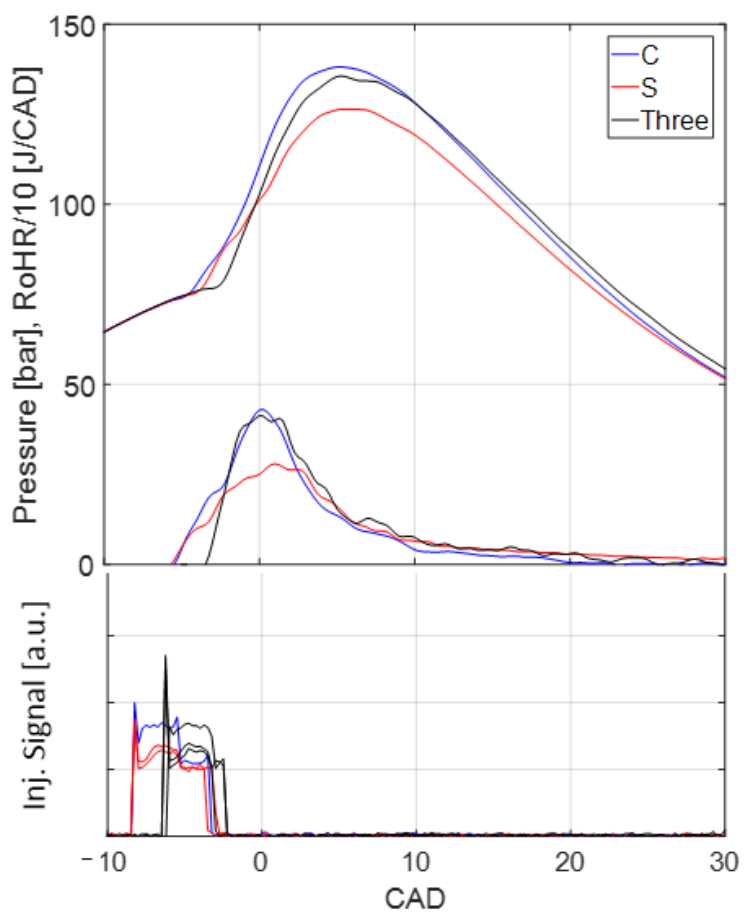

Figure 6, Pressure and RoHR for the single-injection cases

To match the maximum pressure after the second injection, the injection time was slightly adjusted for the different Sabathe cases (see Figure 8 and Figure 9). The faster combustion rate from the first central injection for the $\mathrm{CC}$ and $\mathrm{CS}$ cases causes the higher pressurerise around TDC. This, in turn, causes the higher work amount produced for these cases compared to the SS and SC cases. Thus, it is concluded that a centrally placed injector is useful for combustion control. It is also concluded that the fewer nozzle holes of the $\mathrm{S}$ case make combustion control more difficult.

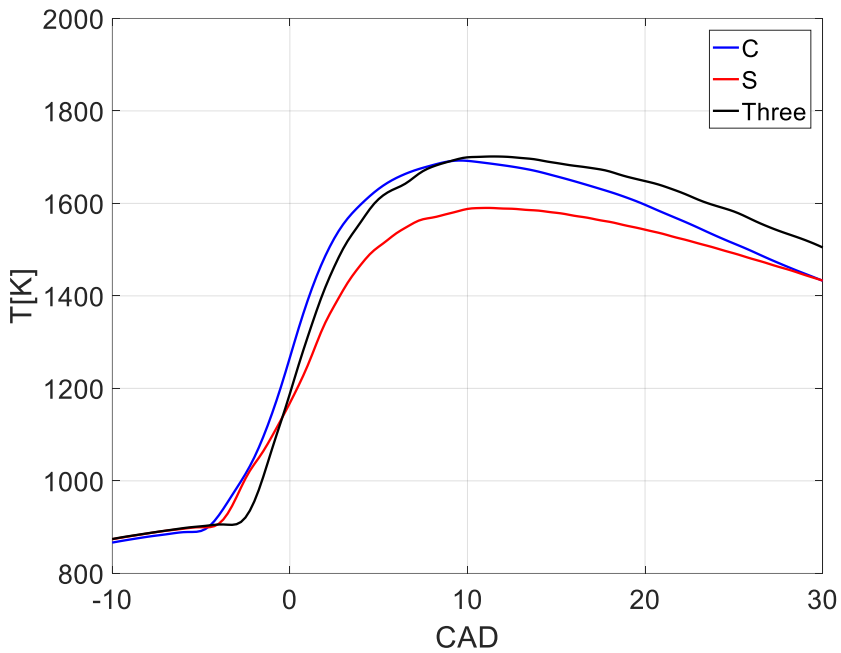

Figure 7, In-cylinder temperature as function of CAD for the singleinjection cases

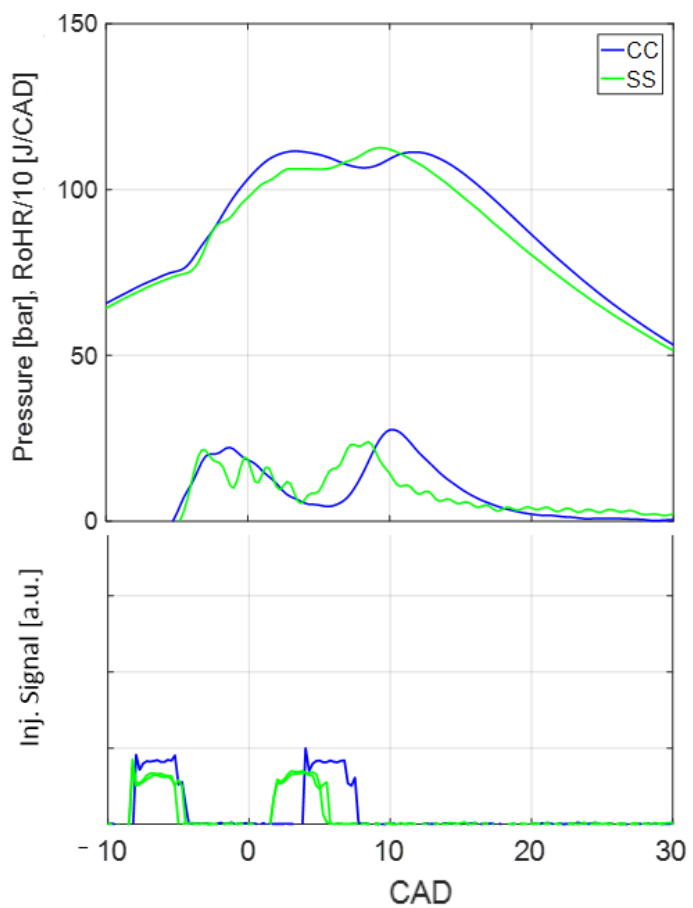

Figure 8, Pressure and RoHR for the CC and SS Sabathe-cycle cases

It is notable that the injection constellation, as compared between the SC and CS cases, does not matter much for the second injection. Here the RoHR behaves in a similar manner (see Figure 9). Thus, the second injection is not much dependent on injector configuration, but rather flow rate, when it comes to heat release. It is also reasonable to conclude that the CC case, spraying the second injection into the same area as the first injection, is not utilizing the air fully. This will be discussed when analyzing the optical images.

When analyzing the in-cylinder temperature (see Figure 10) it is seen that the CS case experience higher temperature compared to the SS and SC cases. This occurs although the heat losses are lower for the CS case as discussed earlier. However, the high heat loss case CC also experiences high in-cylinder temperature. It is thus concluded that there is not a strict correlation between the average in-cylinder temperature and heat losses for these cases. 


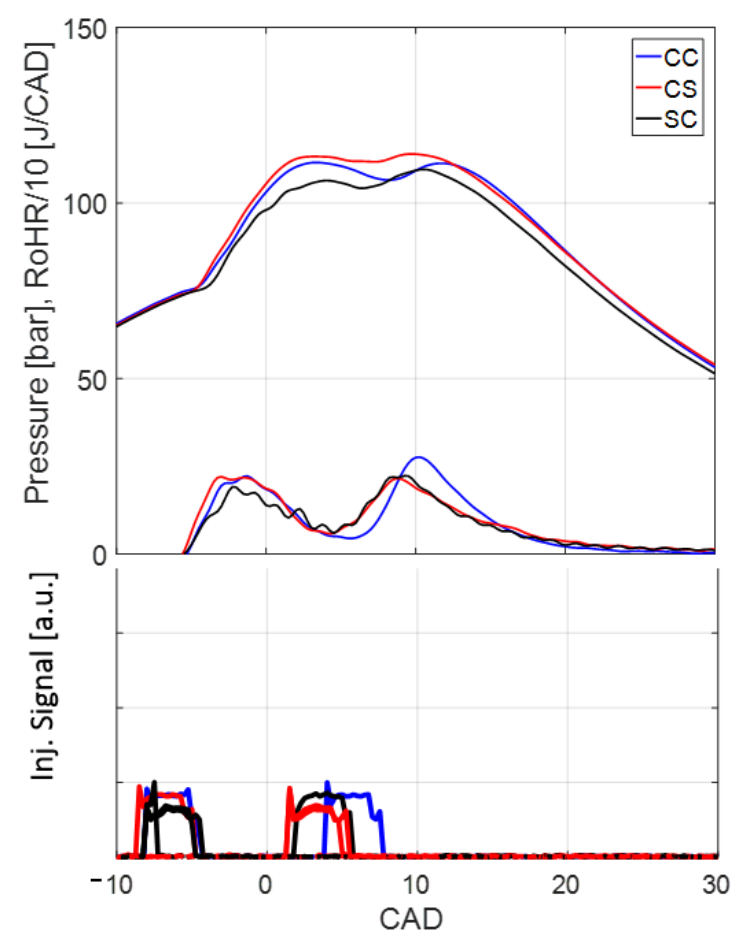

Figure 9, Pressure and RoHR for the CC, CS and SC Sabathe-cycle cases

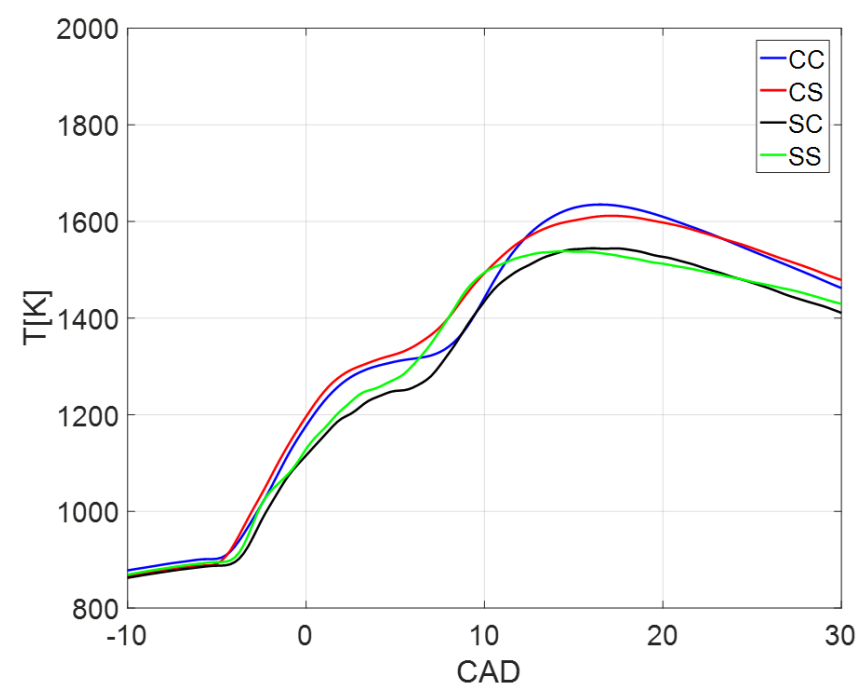

Figure 10, Average in-cylinder temperature for the Sabathe-cycle cases

The low early temperature from the SS and SC cases further confirms the low heat release rate when utilizing the side injectors for the initial injection. For the CC and CS cases, utilizing the central injector for the initial injection, the early temperature rise is close to identical as expected. However, the secondary temperature rise differs. This is partly explained by the inability to match the maximum pressure as discussed earlier exactly. However, the lower secondary temperature rise for the CS case also suggests that the combustion behaves differently and is thus of interest to investigate further.

Page 7 of 11
The fact that all the Sabathe-cycle cases, except the CS case, experience similar heat losses was discussed earlier. Optical bottomview temperature contours (see Figure 11) suggest that the CS case experience the bulk of combustion close to the chamber center. The local hot zones are kept away from the piston wall to a larger extent than for the other cases. The CC case, similarly to the C-case, experience the hot zones pushed towards the piston walls meaning increased heat losses. When only utilizing the central injector for the first injection, as the CS case, this behavior is not observed. Thus, it is again concluded useful to use all three injectors. The black spray tip areas for the CS case are probably due to adhesion of soot, although a final conclusion cannot be drawn.

The SC case experiences almost the entire surface covered by a high temperature at $10 \mathrm{CAD}$ ATDC. Together with the behavior seen for the $\mathrm{CC}$ case, it is concluded that a second injection from the central injector is not beneficial since it pushes the hot zones towards the piston wall. For the SS case, the hot zones close to the piston wall are not significant. However, as discussed earlier, the RoHR is slower, meaning a longer exposure time of hot zones, as seen in Figure 11 with the late increase in average in-cylinder temperature.

To summarize this section, multiple injectors are concluded beneficial for reduced heat losses as well as combustion control. For a single injection, the Three case was found most beneficial in terms of simultaneous high work output and low heat losses. The CS case was found the most beneficial among the Sabathe cases, also due to its concomitant low heat loss and high work output.

\section{Emissions Analysis}

Local emissions have been targeted for reduction in this study. The trade-off between efficiency and NOx emissions were discussed earlier. The higher temperature related to lower heat losses and increased work output is also associated with higher NOx emissions. A reduced heat loss leads to more energy kept inside the combustion chamber and thus a higher temperature. High work output is created from fast combustion leading to high in-cylinder temperature. In this section, this efficiency-NOx trade-off is investigated when utilizing multiple injectors. Further analysis of $\mathrm{HC}, \mathrm{CO}$, and soot emissions will also be presented in this section.

As seen in Figure 12, the $\mathrm{C}$ case experiences the highest NOx emissions, and the heat losses are high. For all cases utilizing multiple injectors, the NOx emissions are thus lower compared to the reference case. The multiple injector Sabathe cases also experience lower NOx levels compared to the CC case. It follows that the multiple injectors are concluded beneficial for low NOx emissions in a CI engine. As expected, the low temperature cases SS, SC and S also have the lowest NOx levels. However, it is notable that the low heat loss case, CS, also results in comparably low NOx-levels. This proves that the impact of the trade-off between high efficiency and NOx is diminished when utilizing multiple injectors. 


\section{CC-case:}

OCAD

$10 \mathrm{CAD}$

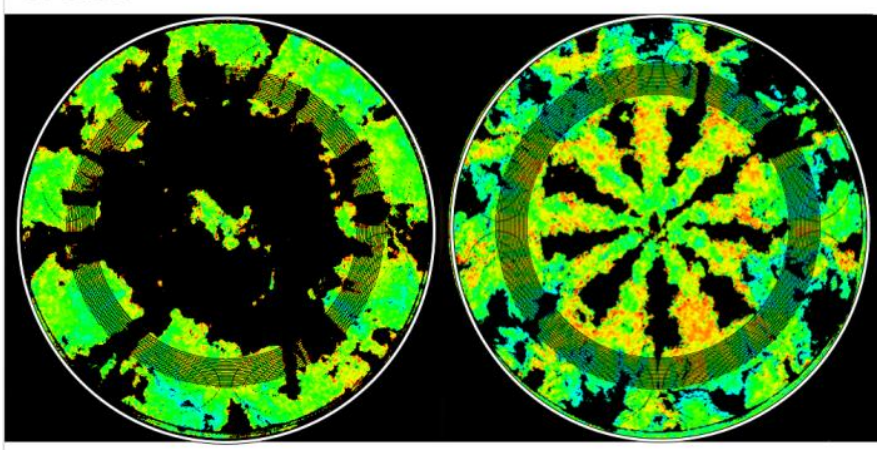

CS-case:

OCAD

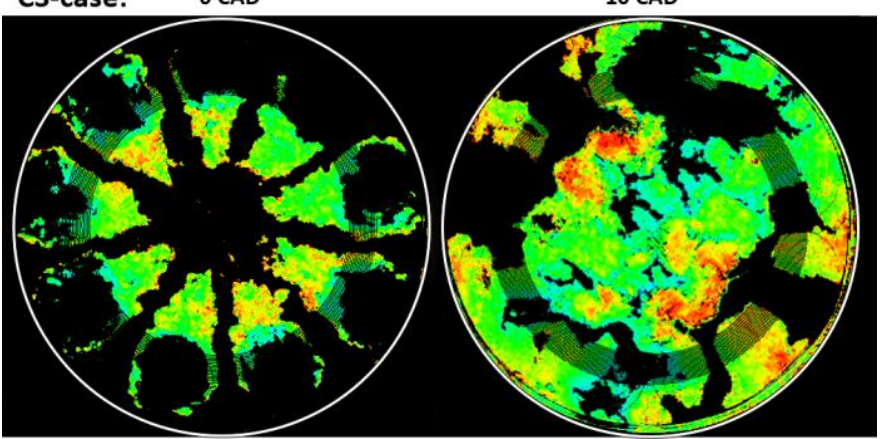

SC-case: $\quad 0$ CAD

10 CAD
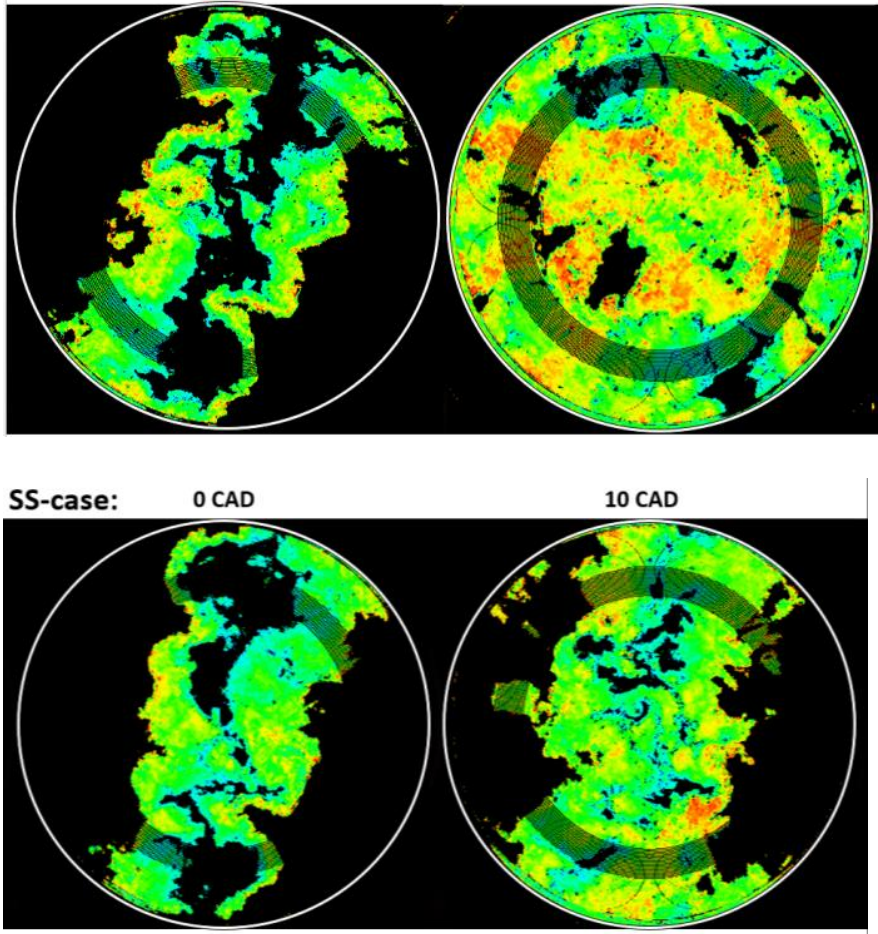

Figure 11, Optical temperature contours for the Sabathe-cycle cases

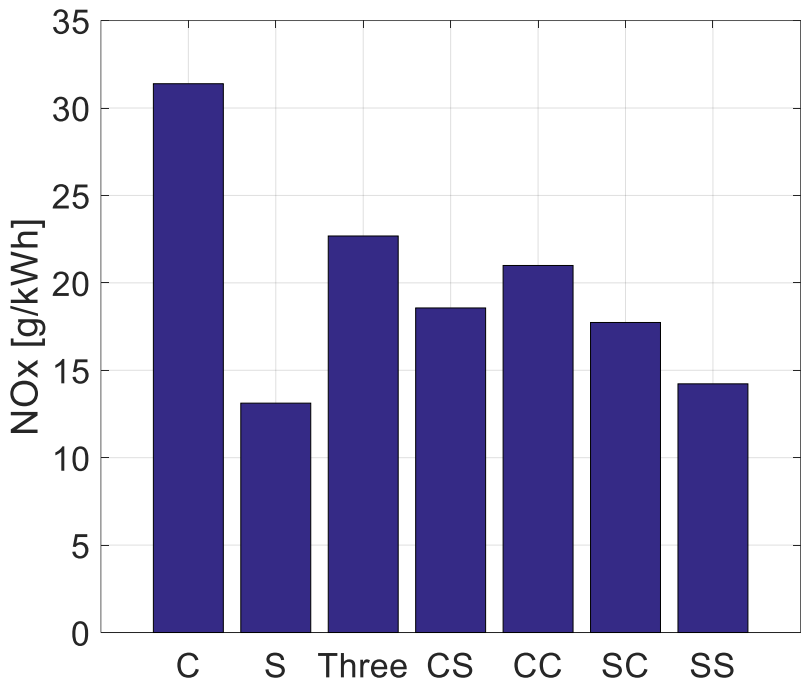

Figure 12, NOx emissions [g/KWh] for all cases

Regarding Soot levels (see Figure 13), there is no clear trend for single vs. multiple injectors. However, the levels increase when using both the central and side injectors for the Sabathe cases. It is also notable that the highest soot levels are found for multiple injections cases. This is possibly explained by the reduced oxidation time when injecting late. For the single-injection cases, the Three case has the lowest soot levels (second lowest overall). The $\mathrm{S}$ case does not increase the soot levels to any larger extent compared to the $\mathrm{C}$ case. Thus, the soot levels do not increase with more injectors. This is contradictory to what was discussed regarding the Sabathe cases. Thus, there is no clear picture of how multiple injectors can be utilized for soot reduction. Therefore, the soot levels for multiple injector cases is an interesting study for future research.

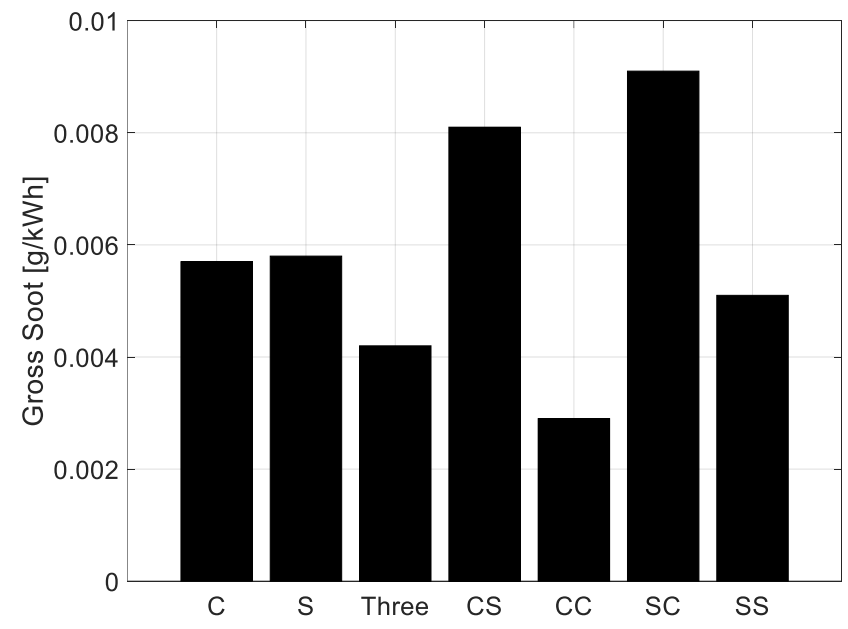

Figure 13, Gross soot levels [g/KWh] for all cases

Unburned $\mathrm{HC}$ is a measure of combustion efficiency and an indication of the injector sack volume fuel quantity for a CI case. When utilizing multiple injectors and multiple injections, the sack volumes will also multiply, and more fuel is expected there. This studies' multiple injector setup is not beneficial for HC emissions (see Figure 14). The $\mathrm{C}$ and $\mathrm{CC}$ cases experience the lowest HC emissions. This indicates that a larger amount of fuel ends up in the sack volume when utilizing the side injectors, as expected.

Page 8 of 11 


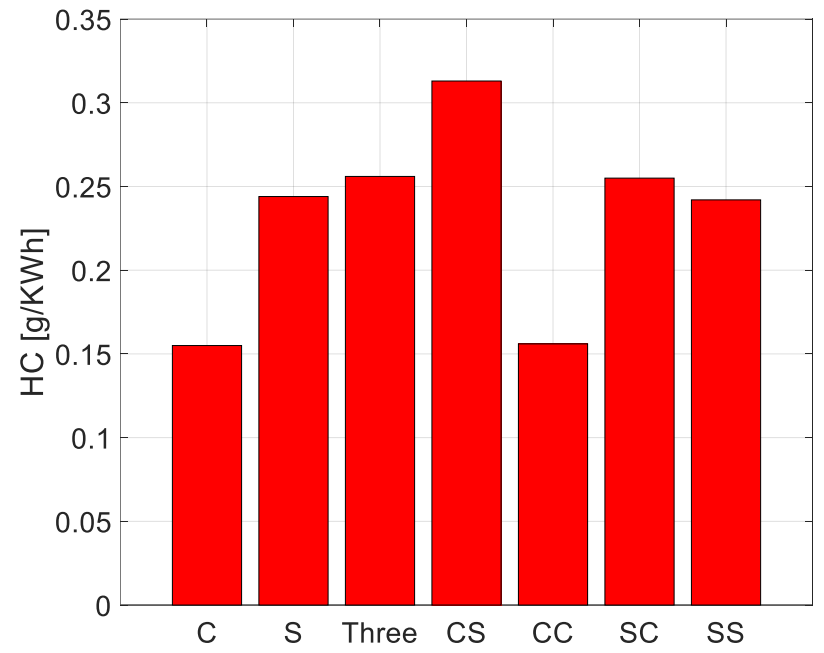

Figure 14, Unburned hydrocarbons [g/KWh] for the different cases

Another measure of combustion efficiency are the $\mathrm{CO}$ emissions. Similarly to the $\mathrm{HC}$ emissions, the $\mathrm{CO}$ emissions are lowest for the cases utilizing only a central injector (see Figure 15). As discussed before, the lowest rate of heat release was found for the cases having an initial side injection. The explanation for this is a combination of piston interaction and worse mixing. These cases ( $\mathrm{S}, \mathrm{SC}$, and $\mathrm{SS}$ ) also experience high $\mathrm{CO}$ emissions as expected. The Three case results in $\mathrm{CO}$ levels close to that of the $\mathrm{C}$ case meaning acceptable heights.

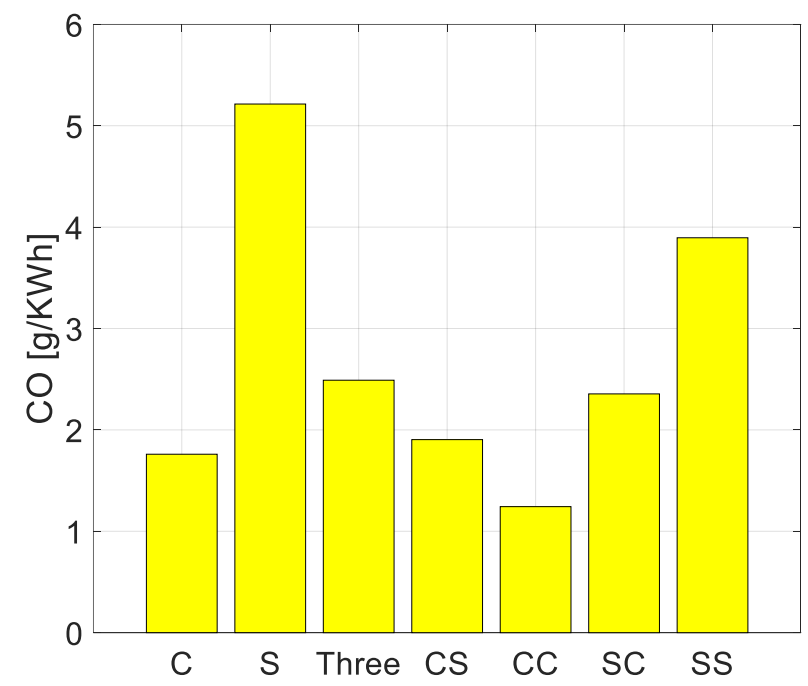

Figure 15, CO emissions $[\mathrm{g} / \mathrm{kWh}$ ] showing the differences between all cases

To summarize the emissions section, the low heat-loss and highefficiency cases, CS and Three, experience reasonable emissions levels compared to the $\mathrm{C}$ case. Emissions formation is, however, a complex chemical process. Thus, further studies are needed to investigate how emissions can be reduced when utilizing multiple injectors.

\section{Total Efficiency Gain, Utilizing a WHR System}

In order to summarize the overall efficiency gain, all areas of improvement must be considered. Decreased heat losses do not themselves deliver higher efficiency. However, the increased exhaust energy (EXMEP) that follows can be utilized in a WHR system. Such a system has been discussed in this study, namely the DCEE. Earlier studies have suggested an expansion efficiency of $75 \%$ for such a concept. Thus, $75 \%$ of the increased EXMEP can be transformed into useful work.

The most substantial heat loss reduction compared to the $\mathrm{C}$ case was found for the CS case, namely $4.1 \%$-points. This resulted in an EXMEP increase of $2.1 \%$-points. Thus, an efficiency increase of around $1.6 \%$-points can be achieved in a DCEE concept. Together with the already increased brake efficiency of $0.6 \%$-points, a total efficiency gain of $2.2 \%$-points is achieved. This is when using both a Sabathe cycle and multiple injectors. The same efficiency gain for the $\mathrm{CC}$ case is around $1 \%$-point. Thus, an efficiency improvement of approximately $1.2 \%$-points is achieved when using multiple injectors at this load point.

For the single-injection case, the Three case has an increased EXMEP of $1.7 \%$-points. This, together with the increased brake work of $0.6 \%$-points means a total of $1.9 \%$-points efficiency increase in the DCEE concept. For the S case, the efficiency is increased by $1 \%$-point in the DCEE concept due to the EXMEP increase of $3.9 \%$-points.

It should be noted that no optimization was performed for this study and that further improvements are possible. Thus, it is concluded that multiple injectors in general increase the efficiency in heavy-duty diesel engines.

\section{Summary/Conclusions}

Metal and optical experiments were performed on a heavy-duty single cylinder CI engine in order to investigate the benefits of utilizing multiple injectors. Experiments for one, two and three injectors were performed with a single as well as multiple injections. Main conclusions are listed as follows:

- $\quad$ Efficiency increased by $1.9 \%$-points when utilizing three injectors in a single-injection DCEE concept

- Side injectors, placed at the rim of the bowl, increase the efficiency by $1 \%$-point for the single-injection case in a DCEE concept

- Multiple injectors increase efficiency up to $1.2 \%$-points for a two-injection Sabathe-cycle case as compared to the oneinjector case

- The increased flow rate of three injectors is beneficial for increasing the work output

- Using three injectors (with single or multiple injections) diminishes the trade-off between low heat losses and high work output

- $\quad$ Side injectors for this constellation experience slow combustion due to the large hole diameter followed by less mixing

- NOx levels are reduced when utilizing multiple injectors

- HC levels are increased with the multiple injector constellation 


\section{References}

1. European Commission, "Reducing CO2 emissions from heavyduty vehicles", https://ec.europa.eu/clima/policies/transport/vehicles/heavy_en (accessed 2018-05-10)

2. European Environment Agency, "Carbon dioxide emissions from Europe's heavy-duty vehicles" https://www.eea.europa.eu/themes/transport/heavy-dutyvehicles/carbon-dioxide-emissions-europe (accessed 2018-0923)

3. Caton JA., "Comparisons of Global Heat Transfer Correlations for Conventional and High Efficiency Reciprocating Engines" ASME Internal Combustion Engine Division Fall Technical Conference, ASME 2011 Internal Combustion Engine Division Fall Technical Conference: 327-337, doi:10.1115/ICEF201160017.

4. Sjöberg, M. and Dec, J., "Combined Effects of Fuel-Type and Engine Speed on Intake Temperature Requirements and Completeness of Bulk-Gas Reactions for HCCI Combustion," SAE Technical Paper 2003-01-3173, 2003, doi: 10.4271/200301-3173.

5. Noehre, C., Andersson, M., Johansson, B., and Hultqvist, A., "Characterization of Partially Premixed Combustion," SAE Technical Paper 2006-01-3412, 2006, doi: 10.4271/2006-013412.

6. Manente, V., Johansson, B., Tunestal, P., and Cannella, W., "Effects of Different Type of Gasoline Fuels on Heavy Duty Partially Premixed Combustion," SAE Int. J. Engines 2(2):7188, 2010, doi: 10.4271/2009-01-2668.

7. Caton, Jerald A. "Maximum efficiencies for internal combustion engines: Thermodynamic limitations." International Journal of Engine Research 19.10 (2018): 1005-1023.

8. Lam, N., Andersson, A., and Tunestal, P., "Double Compression Expansion Engine Concepts: Efficiency Analysis over a Load Range", SAE Technical Paper 2018-01-0886, 2018, doi:10.4271/2018-01-0886.

9. Lam, N., Tuner, M., Tunestal, P., Andersson, A. et al., "Double Compression Expansion Engine Concepts: A Path to High Efficiency," SAE Int. J. Engines 8(4):2015, doi:10.4271/201501-1260.

10. European Commision, "Air Pollution from the Main Sources", http://ec.europa.eu/environment/air/sources/road.htm (accessed 2019-03-15)

11. Okamoto, T. and Uchida, N., "New Concept for Overcoming the Trade-Off between Thermal Efficiency, Each Loss and Exhaust Emissions in a Heavy Duty Diesel Engine," SAE Int. J. Engines 9(2):2016, doi:10.4271/2016-01-0729.

12. Amin, H. M., \& Roberts, W. L., "Soot measurements by two angle scattering and extinction in an N2-diluted ethylene/air counterflow diffusion flame from 2 to $5 \mathrm{~atm}$ ", Proceedings of the Combustion Institute, 36(1), 861-869, 2017.

13. Enya.K., Watanabe, H. and Uchida, N., "Investigation into the Optimized Heat Release Rate and Corresponding Variation of In-Cylinder Specific Heat Ratio for the Improvement in Thermal Efficiency by Utilizing Two-Zone Combustion Model Analysis", SAE Technical Paper 2018-01-1796, 2018, doi:10.4271/2018-01-1796.

14. Nyrenstedt. G, Al Turkestani. T, Im. H and Johansson.B, "CFD Study of Heat Transfer Reduction Using Multiple Injectors in a DCEE concept" SAE Technical Paper 2019-01-0070, 2019, doi: 10.4271/2019-01-0070

15. Nyrenstedt, G., Im, H., Andersson, A., and Johansson, B., "Novel Geometry Reaching High Efficiency for Multiple
Injector Concepts," SAE Technical Paper 2019-01-0246, 2019, doi: 10.4271/2019-01-0246

16. Uchida N, Watanabe H., "A new concept of actively controlled rate of diesel combustion (ACCORDIC): Part II-simultaneous improvements in brake thermal efficiency and heat loss with modified nozzles", International Journal of Engine Research. 2019 Jan;20(1):34-45.

17. Tsurushima, T., Harada, A., Iwashiro, Y., Enomoto, Y., Asaumi, Y., and Aoyagi, Y., "Thermodynamic Characteristics of Premixed Compression Ignition Combustions", SAE Technical Paper 2001-01-1891, 2001, DOI:10.4271/2001-011891.

18. Kamimoto T, Uchida N, Aizawa T, Kondo K, Kuboyama T. "Diesel flame imaging and quantitative analysis of in-cylinder soot oxidation. International Journal of Engine Research", 2017 Aug; 18(5-6):422-35.

19. H.C.Hottel \& F.P.Broughton, Industrial and Engineering Chemistry, 4,2 ,pp.166-74

20. Y.Matsui, T.Kamimoto, S.Matsuoka, A.OGYRI "A Study on the Measurement of Flame Temperature in Diesel Engines" JSAE 44(377), P228-238, 1978

21. Li J, Yang WM, An H, Chou SK., "Modeling on blend gasoline/diesel fuel combustion in a direct injection diesel engine", Applied energy. 2015 Dec 15;160:777-83.

\section{Contact Information}

Gustav Nyrenstedt

Ph.D. Candidate

Clean Combustion Research Center (CCRC)

King Abdullah University of Science and Technology (KAUST)

23955-6900 Thuwal, Saudi Arabia

sven.nyrenstedt@kaust.edu.sa

Phone no: +966 (0)56 0458328

\section{Acknowledgments}

The authors would like to thank the N.A.C.E. consortium in Tsukuba, Japan for funding and support in terms of experimental setup. The authors would further like to thank the Clean Combustion Research Center at KAUST for support and funding.

Page 10 of 11 


\section{Definitions/Abbreviations}

ATDC

BDC

CA50

CAD

CO

$\mathrm{CO}_{2}$

Cylinder Wall

DCEE

EXMEP

HC

HCCI

IMEPg

IMEPn

NOx

Soot

PPC

RoHR

SOI

TDC

WHR
After top dead center

Bottom dead center

Crank angle degree at which $50 \%$ of the heat is released

Crank angle degrees

Carbon monoxide

Carbon dioxide

Liner, piston and head boundaries

Double compression expansion engine

Exhaust mean effective pressure

Hydrocarbons

Homogenous charge compression ignition

Gross indicated mean effective pressure

Net indicated mean effective pressure

Nitric oxides

Particle matter

Partially premixed combustion

Rate of heat release

Start of injection

Top dead center

Waste heat recovery 